\title{
CULTURAL VALUES IN THE POETRY OF CIANJUR POETS
}

\author{
Lala Latifah \\ Universitas Suryakaancana, Cianjur \\ email: lalalatifah594@gmail.com
}

\begin{abstract}
This article will discuss cultural values in the poetry of Cianjur poets. The method used in this research is descriptive method. Data sources are two anthologies of poetry, namely "Selalu Ada Rindu" a collaborative work of the poets of Cianjur and "Jejak" by Edwar Maulana. From the analysis, results of research are obtained, those are, there are 10 cultural values relating to the nature of human life: weir of evil, tawadhu, sympathy, khusyu, pray, tawakal, tasyakur, arraja'a, wisdom, and preventing persecution. Human work has 7 cultural values, namely business, provision, preventing persecution, creating, adding knowledge/insight, courage and ideals. Human position in space and time has 8 cultural values, namely sympathy, peace, arraj'a, love of nature, tasyakur, love, solemnness, effort and provision. Human relations with natural surroundings has 7 cultural values namely loving nature, sympathy/feeling what others feel, ideals, peace, perseverance, and exploiting nature. Then human relations with each other have 11 cultural values namely courage, love, prayer, provision, ideals, creating, endeavoring, respecting, tasyakur, khusyu, and utilizing nature.
\end{abstract}

Keywords: cultural value, poetry, poet, Cianjur

\section{PENDAHULUAN}

Puisi para penyair Cianjur adalah puisi yang menggugah dan memiliki kekuatan isi yang bermanfaat. Sesuai dengan teori bahwa puisi adalah bentuk karya sastra yang mengungkapkan pikiran dan perasaan penyair secara imajinatif dan disusun dengan mengonsentrasikan semua kekuatan bahasa, struktur fisik dan struktur batinnya. (Waluyo, 1995: 25).

Puisi tersebut ditulis oleh beberapa penyair Cianjur yang memiliki latar belakang berbeda tentunya, Tetapi memiliki sisi kesamaan dalam isi puisi yang memiliki nilai budaya. Hal ini penting diteliti untuk melihat bagaimana nilai budaya yang terdapat dalam puisi para penyair Cianjur sehingga menjadi cerminan budaya pada masyarakat daerah tersebut. Menurut Kluckhon (Soelaeman, 2000: 42-43) dalam kehidupan manusia memiliki sistem budaya, dan dari semua sistem kebudayaan yang ada berkaitan dengan lima pokok masalah, yaitu (1) mengenai hakikat hidup manusia, (2) mengenai karya manusia, (3) mengenai hakikat dari hubungan waktu, (4) mengenai hakikat dari hubungan manusia dengan alam sekitarnya, (5) mengenai hakikat dan hubungan manusia dengan sesama.

Nilai-nilai budaya tersebut yang harus menjadi pedoman atau pegangan dalam kehidupan di masyarakatnya. Sementara jika melihat keadaan masyarakat sekarang dengan kemunculan teknologi dan cepatnya bertukar informasi tidak saja memberikan dampak positif tetapi juga memiliki dampak negatif salah satunya adalah terjadinya perubahan dan pergeseran nilai budaya sehingga dengan sendirinya mental manusia akan terpengaruh. Jika budaya yang ada sudah berubah akan menimbulkan rusaknya tata nilai pada masyarakat, sehingga akan terjadi dehumansi atau pengurangan arti nilai-nilai kemanusiaan. Contohnya dalam dunia 
pendidikan misalnya maraknya tawuran antar pelajar, atau pelecehan seksual pada pelajar. Hal itulah yang menjadi latar belakang masalah, sehingga dilakukannya penelitian.

Dengan meneliti nilai-nilai budaya yang ada dalam puisi penyair Cianjur, dapat diketahui nilai yang terdapat di daerah tersebut, yang akan dengan mudah menerapakan dalam kehidupan dan dapat terhindar dari terjadinya dehumansi yang dapat merusak mental masyarakat karena budaya adalah pikiran dan akal budi. Budaya juga merupakan keseluruhan sistem gagasan tindakan dan hasil karya manusia dalam rangka kehidupan masyarakat yang dijadikan milik diri manusia dengan cara belajar. (Nasution, 2015: 15).

Penelitian lain yang dianggap relevan adalah penelitian Munsi, (2014) yang mendeskripsikan romantisme, juga mendeskripsikan nilai-nilai budaya yang ada dalam puisi karya Yusuf Gigan. Penyair tersebut merupakan salah satu penyair Cianjur, yang membahas mengenai tempat bersejarah di Cianjur, tokoh-tokoh Cianjur yang semua itu termasuk ke dalam nilai-nilai budaya.

Jika dalam penelitian tersebut medeskripsikan nilai budaya dalam satu orang penyair, sedangkan penelitian yang telah dilakukan mendeskripsikan nilai-nilai budaya dalam puisi beberapa penyair Cianjur. Hal ini penting dilakukan karena untuk mengetahui kesamaan ataupun perbedaan nilai-nilai budaya dari penyair satu dengan yang lainnya. Selain itu, penelitian karya sastra perlu dilakukan untuk mengetahui dan melihat relevansi isi karya sastra dengan kehidupan masyarakat (Indriani, 2003: 4).

\section{METODE}

Metode yang digunakan ketika melaksanakan penelitian adalah metode deskriptif. Metode tersebut digunakan untuk mendeskripsikan nilai-nilai budaya dalam puisi penyair Cianjurkhususnya puisi dalam dua antologi yaitu "Selalu Ada Rindu" karya bersama para penyair Cianjur dan "Jejak" karya Edwar Maulana.

Dari kedua antologi itu ditelaah puisi dari sepuluh penyair Cianjur yaitu Zahra Madania, selanjutnya disingkat ZM, Dede Muharam, disingkat DM, Fahd Djibran, disingkat FD, Faizal Syahreza, disingkat FS, Ikhsan Subhan, disingkat IS, Lia Kurniasih, disingkat LK, Syaeful Anwar, disingkat SA, Syifa Sujud, disingkat SS, Yusuf Gigan, disingkat YG, dan Edwar Maulana, disingkat EM.

\section{HASIL DAN PEMBAHASAN}

Nilai budaya merupakan kegiatan mengkaji konsep-konsep yang berupa nilai, moral, norma, dan keyakinan (belief) manusia yang ada di dalam masyarakat yang sangat penting dan bernilai dalam kehidupan. Sesuai dengan teori Kluckhon bahwa nilai budaya secara universal menyangkut lima masalah pokok di dalam kehidupan manusia, yaitu hakikat hidup manusia, hakikat karya manusia, hakikat waktu manusia, hakikat alam manusia, dan hakikat hubungan manusia. Kelima masalah tersebut merupakan alat analisis nilai-nilai budaya sebanyak 50 (lima puluh) puisi. Berikut ini merupakan analisis dari kelima puluh puisi tersebut.

\section{Hakikat Hidup Manusia}

Jika dilihat dari segi bahasa hakikat merupakan segala sesuatu yang sebenarbenarnya. Atau dapat dikatakan hakikat itu inti dari segala hal. Sehingga sebagai makhluk ciptaan Tuhan, hakikat dari hidup manusia adalah harus senantiasa menjalankan segala perintahnya dan menjauhi segala larangannya. Jadi aktivitas yang dilakukan manusia adalah yang perintah Tuhan, dan menjauhi aktivitas adalah larangan Tuhan. Hal tersebut berarti segala aktivitas manusia dibangun atas dasar rasa keimanan yang tumbuh dalam diri manusia karena setiap aktivitas yang dijalanan oleh manusia harus sesuai dengan aturan yang ditetapkan Tuhan. 
Tuhan telah menitipkan akal kepada manusia agar setiap melakukan aktivitasnya terlebih dahulu mengkaji langkah-langkah yang benar agar sesuai dengan apa yang dituntut Tuhan semesta alam yang telah mengatur semua perbuatan manusia. Berkenaan dengan nilai budaya berupa hakikat hidup manusia, nilai budaya yang terkandung dalam puisi para penyair Cianjur, selalu mengingatkan manusia agar senantiasa mengingat Tuhan dalam segala aktivitasnya.

Berikut ini adalah kutipan puisinya.

Dan sekarang aku kembali ke padang rumput. Bermain rakit dengan

ikan, atau mencium angin. Sambil beristirahat dari kesibukan modern,

menjauhi kebisingan motor yang merubah suara serulingku menjadi

geraman jaman. Sungguh hanya ini yang bisa menjadi tempat aku

berhenti. Dan disini pula rasanya tempat aku ingin mati. Pergi.

Meninggalkan mereka yang akan terus merajut dosa sampai tua Bangka.

(F.S: BND KJHT)

Puisi di atas berisi ingin pergi dari segala kemaksiatan yang dilakukan manusia di tengah kehidupan yang penuh dengan kebisingan pada zaman yang modern seperti sekarang ini, sehingga sebagai manusia ia hanya bisa berusaha membendung kejahatan dengan cara pargi dari tempat tersebut yang tentunya lebih damai dan terhindar dari kejahatan manusia yang sedang merajut dosa.

Kemanapun melamun

Kemanapun menukar uang

Waktu memotong jiwamu

Kau jangan bersembunyi

Menyelinap kegelisahan

Bilapun engkau putarkan lagi uang

Mencampuradukan keinginan

Nasib terus memberat ditanganmu

(I.S: BND

KJHT)
Ketika melakukan aktivitas yang tidak ada gunanya bahkan merusak kehidupan akan terjerumus dalam kegelapan, waktu akan terbuang sia-sia, hidup akan dipenuhi kegelisahan, dan sulit menentukan nasib hidup untuk kedepannya, seperti makna dalam puisi di atas. Dengan demikian, tugas manusia perlu berusaha untuk tidak melakukan hal yang seperti itu atau membendung kejahatan yang akan merusak kehidupan kita.

Tsunami
menyapa mereka
adalah dzikir
adalah wirid
adalah ayat-ayat laut

(S.S: TWDH)

Tuhan memberi cobaan atas bencana dan sebagi manusia harus senantiasa tawadhu, atau sabar menerimanya. Dengan memiliki sifat tawadhu akan menerima dan menyadari bahwa bencana tersebut adalah pengingat agar taat terhadap aturan Tuhan termasuk menjaga alam semesta.

\section{Aku tak mampu menyelamatkan orang-orang dari rasa lapar dan cemburu berkepanjangan.}

(E.M: SMPT)

Manusia adalah makhluk sosial yang tidak bisa hidup secara mandiri. Sebagai makhluk sosial, harus memiliki sifat simpati kepada sesama agar senantiasa hidup dengan rukun, seperti isi yang puisi di atas.

Di malam hari!Izrali kembali datang menarik nafas kehidupan,

aku pun berkata sedikit tak bernada, sedikit terbata-bata:

"Sebenarnya kepada Engkaulah ingin kuungkapkan rasa!"

(A.Z: KHSY)

Tuhan,

Aku masih bersujud mengetuk pintu $\mathrm{Hati}-\mathrm{Mu}$

Masih seperti dulu, dalam do'aku: 
(A.Z: KHSY, DOA)

Dan biarkan Kau tetap menjadi cinta sejatiku.

Ketika kehilangan datang,

Ketika kehilangan, Bulan Ramadhan.

(A.Z: KHSY)

kuberikan doaku yang terakhir

Setelah jasadmu kaku di kebisuan waktu.

(D.M: DOA)

Tuhan inilah cintaku,

Takan mati

Tiap gerak adalah tasbih

(D.M: KHSY)

melingkari titik Tuhan.

(D.M: KHSY)

Ayahku menggumam doa,

lebih mirip puisi.

Bibirnya bergerak tanpa henti,

sesekali memejamkan mata.

(F.D: DOA)

Aku menyerah, Tuhan

Aku benar-benar merasa anomik

Inilah, kukembalikan lagi hidupku pada-Mu

Sebab hidup adalah milik-Mu

(F.D: KHSY)

Dan matahari berevolusi

Seratus cahaya, seratus kegelapan

Bergolak dalam doaku

jubah lepas dari seluruh khilafku,

telah aku tepikan nikmat diujung tanah

meniti air menghilir doa.

(L.K: DOA)

Khusyu dan addu'a adalah menyerahkan doa pengharapan dengan penuh penyerahan dan kerendahan hati kepada Tuhan.

ku titipkan engkau pada-Nya Anakku

(S.A: DOA, TWK)

Maka dengan sepenuh doa

fajar ini ku lepaskan engkau menuju pengembaraanmu melepaskan pelukanku yang selama ini menemani tidurmu

mengeringkan air susu penyambung

kehidupanmu

agar kau bisa berdiri sendiri

dan mampu menggantinya dengan kejernihan hujan

(S.A: DOA)

pagi kuraba ku pandang matahari dan pepohonan

jadi doa yang kutemukan

dilantai-lantai sejarah para nabi

lalu kukekalkan rakaat

(S.S: DOA)

di malam pembukaan penuh rahmat

atas wujud HusnaMu yang sempurna

atasMaha lembutMu dimana-mana

(S.S: TSY)

Tasyakur sebagai bukti rasa syukur manusia kepada Tuhan dengan cara beribadah kepada-Nya. Seperti dalam larik di atas.

Ya Murba,

kukabarkan dari negeri cinta

pada sembahyang 81ala mini

saat mereka kau matikan sejenak

terkemas dzikir

(S.S: KHSY)

Ya Murba

Pada sujud 81ala mini

kuadukan permohonan

sejak darah-darah kecilku

siramilah mereka dengan

keberkahanmu

hingga mukanya tidak tertutup debu

kekal dalam mata hati mereka

adil menempatkan dua pandangan

hingga saat mereka asing

tiada tersirat

wajah benci

Kekasih,

(S.S40: L10-20: KHSY, DOA)

setelah bayangan air di tanahmu membukakan segala debu ditubuhku aku mempercayai sebuah keimanan atas nama pemilik semesta

(Y.G43: L1-5: TSYK) 
Doa-doa berhening dalam kalimat-kalimat paling sunyi.

(Y.G: DOA)

Pada setiap sujudku di padang rumput, aku mendengar suara angin menggoyangkan bunga. Juga aku yang ikut bergaya di antara cakrawala Danau sebagaimana cermin mega, disana aku mebuat rakit untuk bermain dengan ikan-ikan. Agar aku kenal dunia air yang tidak suram.

(F.S: ARJ, TWK)

pergilah mencari impianmu di segala kemungkinan carilah apapun yang kau rasa berarti lalu, pulanglah padaku saat saat kau temukan segalanya "jampe-jampe harupat" "geura gede geura lumpat"

(S.A: KSH)

Pada langkah kaki

juga janji sumpah para pendekar

Silat menjadi pegarah ketika dzalim merampas senja

\section{(S.A: MNCG)}

Kita mesti berhati-hati, katamu lagi sebab setiap langkah yang salah menjadi asah baginya, segala keluh menjadi pengasuh kekejamannya.

(E.M: BND KJHT)

Dalam larik-larik di atas berisi rasa syukur, khusyu dan addo'a kepada Tuhan. Karena selaku makhluknya yang bertaqwa hanya kepada Tuhanlah kita meminta dan berserah diri.

Puisi-puisi di atas merupakan termasuk pada nilai-nilai budaya yang berkaitan dengan hakikat hidup yaitu hidup itu Buruk, hidup itu baik dan upaya hidup menjadi baik. Nilainilai budayanya adalah bendung kejahatan (BND KJHT), tawadhu (TWDH), simpati (SMPT), khusyu (KHSY), berdoa (DOA), tawakal (TWK), tasyakur (TSY), arraja'a (ARJ), bijaksana (BJK), dan mencegah penganiayaan (MNCG). Berikut ini adalah kutipan puisinya.

\section{Hakikat Karya Manusia}

Setiap manusia memiliki kebutuhuan dalam hidupnya. Dari mulai kalangan orang yang sederhana sampai dari kalangan atas sekalipun tidak akan terlepas dari hal tersebut. Dari kebutuhan itu, timbul keinginan untuk menciptakan sebuah karya. Melalui bekal akal, dan pikiran manusia dapat membuat sebuah karya untuk keberlangsungan hidupnya. Adapun nilai-nilai budaya yang berkaitan dengan karya manusia, yaitu karya untuk hidup, karya untuk kedudukan, kehormatan dsb, dan karya untuk menambah karya pada puisi penyair Cianjur adalah sebagai berikut.

\section{Membajak di pematang \\ garis-garis wajah mulai menua \\ kebaya ibu mulai lusuh \\ waktu mulai menepi \\ Menuju garis tanah yang juga mulai тепиа \\ Ibu! Padi kita telah lama menguning}

(L.K: USH, BKL)

Larik-larik di atas menunjukan nilai budaya yaitu usaha dan bekal. Sebagai seorang manusia yang dikarunia akal makan manusia akan berusaha untuk bekal dalam hidupnya seperti dengan cara membajak di sawah, meski dilakukan seorang perempuan yang sudah tua, namun demi kebutuhan hidupnya, hal tersebut harus lakoninya.

Pada langkah kaki

Juga janji sumpah para pendekar

Silat menjadi pegarah ketika dzalim merampas senja

(S.A: MCGH)

Larik tersebut menggambarkan, dengan memiliki bekal kemampuan beladiri, maka bisa mencegah kedzoliman, atau kejahatan.

sesungguhnya aku telah menjadi syair yang 
menerbangkan kata-kata disetiap sudut kota.

(D.M: MNCPT, PNGT)

Sebuah sajak singgah di ranjangku

menata ruang yang mulai retak

memilih lukisan yang sembunyi disetiap

perih menunggui batas

mimpi

(L.K: MNCPT)

Malam terlentang
Benderang dari cahaya
Segala pakakas*siap dipencakan
Orang-orang dari semua Pendepokan
Berkumpul menyaksikan arena
pertarungan bersila disudut
Para pendekar
panggung
Dengan pangsi berwarna gelap juga
iket*di kepala
Lalu,
Mereka bersiap adu jajaten*

(S.A: BRN)

Larik tersebut menggambarkan, keberanian para pendekar beladiri atau silat dalam bertarung melawan pasangannya.

di perjalanan ketemulah dengan dengan Pak RT

sekalian, saya lapor diri dan jelaskan bahwa kini

saya menikahi puisi

juga berharap punya keturunan imajinasi

(S.A: MNCPT, CT)

Nilai-nilai budaya di atas berkenaan dengan hakikat karya manusia yaitu, usaha (USH), bekal (BKL), mencegah penganiayaan (MNCG), mencipta (MNCPT), menambah pengetahuan /wawasan (PNGT), berani (BRN) dan cita-cita (CT). Nilai-nilai tersebut merupakan salah satu pegangan hidup manusia agar dapat bertahan dengan cara menghasilkan karya.

\section{Persepsi Manusia Tentang Ruang dan Waktu}

Salah satu makhluk yang istimewa adalah manusa karena ia dikarunia akal yang tidak diberikan kepada makhluk lainnya. Dari akal tersebutlah akan senantiasa berkembang dan dapat dikembangkan. Oleh karena itu manusia akan tetap aktif, tumbuh berkembang dalam masa hidupnya.

Nilai budaya mengenai persepsi manusia tentang ruang dan waktu yaitu orientasi ke masa kini, orientasi ke masa lalu, dan orientasi ke masa depan adalah sebagai berikut.

"Keresahan apa yang kau pancarkan
pagi ini”?
Hari ini, mentari memang tak sehangat
bulan malam tadi,
Aku mengerti,
Dan sedikit membaca tentang
keresahan yang terlintas
Di persembunyian
Mata dan jiwamu.
Bolehkah pagi ini aku menggantikan
kehangatan mentari pagi ini?

(A.Z: SMPT)

Larik di atas menggambarkan, simpati manusia kepada sesamanya ketika sedang mengalami masalah sehingga ia bisa menghiburnya.

Dan sekarang aku kembali ke padang rumput. Bermain rakit dengan ikan, atau mencium angin. Sambil beristirahat dari kesibukan modern, menjauhi kebisingan motor yang merubah suara serulingku menjadi geraman jaman. Sungguh hanya ini yang bisa menjadi tempat aku berhenti. Dan disini pula rasanya tempat aku ingin mati, pergi. Meninggalkan mereka yang akan terus merajut dosa sampai tua bangka.

(F.S: DMI)

Larik di atas menggambarkan merindukan kedamaian, dari hingar bingarnya kesibukan modern dan kebisingan suasana di kota membuatnya ingin meninggalkan kota itu. 
Dalam siang berlanjut gersang

Dedaun memusimkan gugur hati

Malam terakhir dicampakan

Seperti penderitaan angin

Kupu-kupu disayat ribuan cemas

Tatkala datang debu-debu

Rerumputan tersapu

Pinta bumi kepada langit

Habiskan kemarau detik ini pula

(I.S: ARJ, USH)

Larik di atas menggambarkan pengharapan ingin segera hilang musimnya kemarau, karena merasakan alam yang sudah tidak bersahabat lagi.

\section{Pagi selalu terlambat di tempat ini}

Sungguh!

Burung serangga kelaparan

Hujan hilang

(S.A: CNT.A)

Larik di atas menggambarkan cinta terhadap alam, kerinduan pada tempat tersebut, meski keadaanya sangat tidak nyaman.

Hari ini masih terasa sulurNya nyentuh setiap musim betapa elok

(S.S: TSY)

Larik di atas menggambarkan tasyakur atau rasa syukur manusia kepada Tuhan-Nya.

Hari ini masih tak kulupakan kau, dendangan bergemuruh

luruh

malam di hunjam hasrat, tiada tenang

selama terdengar keluh

menantang keputusan

(S.S: KSH)

Larik di atas menggambarkan kasih sayang kepada sesama manusia.

Maka, saat ini

ketika meraka lebih banyak

kehilangan dan jatuh sakit

(E.M: SMPT)

Seketika bayangan masa silam-masih ada tersimpan di Hati yang

Terdalam.
(A.Z: $\mathrm{KSH})$

Wahai !air mata yang telah membasahi kerinduan wajah ini sejak

ribuan tahun tubuhku gelisah dan ketakutan

Ingat kembali tragedi

(D.M: KHSY)

Kubitakan hari esok

Sampai kikis

Seluruh pengap silamku.

(I.S: USH)

Mereka yang terkena ledakan

di dapur yang tak subur

dan anak-anak yang beranjak

dengan pendidikan.

Tak bisa aku selamatkan semuanya

bahkan diriku dari kenangan

mengerikan

dan dari rasa ingin melupakan

(E.M: SMPT)

Larik di atas menggambarkan rasa simpati manusia kepada sesamnya. Sebagai makhluk sosial kita harus bisa saling menyayangi dan bertoleransi.

Jika kau percaya

bahwa bumi pernah lebih baik

dari saat ini.

Dimana orang-orang lebih banyak

menemukan dan jatuh cinta

pada apa saja yang mereka dapati

(E.M: DMI)

Puisi di atas menggambarkan meridukan kedamaian yang tergambarkan ketika masa dulu.

Masa lalu adalah tas di punggungmu yang disesaki banyak angka, huruf dan tanda baca.

(E.M: BKL)

Larik di atas menggambarkan bekal berupa pengetahuan dan pengalaman dalam hidup yang sudah dijalaninya, untuk kehidupan yang akan datang.

Di musim gugur ini, dedaunan siap menggugurkan jasadnya.

Dan tentunya aku harus kembali menumbuhkan Tunas Harapan. 
(A.Z: CT)

Mungkin suatu saat akan kulihat lagi senyummu

Mungkin suatu saat akan kupersembahkan sebuah rumah mewah lengkap dengan halaman belakang yang indah

(F.D: CT)

Menunda masa muda agar tak hilang di masa depan dalam

kenangan. Sebab suatu saat kita harus punya harapan. Kita berkisah-kasih layaknya alam.

(F.S: CT)

Nanti, bawakanlah aku seorang cucu dari kesempurnaan istrimu yang terpilih

dan aku selalu menunggumu di balik pitu ini

Lalu kota-kota berdiri dengan jalanjalan yang panjang. Meraih apa saja yang bisa diraih, mencipta apa saja yang bisa dicipta.

(Y.G: CT)

Sementara masa depan seperti buku kosong dalam dekapanmu yang lelah dan kian melemah.

(E.M: USH, CT)

Larik-larik di atas menggambarkan bahwa manusia memiliki keinginan atau cita-cita demi kehidupannya yang lebih baik di masa mendatang kelak.

Nilai-nilai budaya yang berkenaan dengan persepsi manusia tentang ruang dan waktu pada puisi- puisi di atas adalah simpati (SMPT), damai (DMI), arraj'a (ARJ), cinta alam (CNT.A), tasyakur(TSY), kasih sayang (KSH), khusyuk (KHSY), usaha (USH) dan bekal (BKL).

\section{Pandangan Manusia terhadap Alam}

Tuhan menciptakan makhluknya dengan sempurna, yaitu manusia. Manusia tidak hanya dikaruniai akal untuk bekal hidupnya, namun juga Tuhan memberikan bekal berupa alam untuk memenuhi kebutuhan dalam hidupnya. Tuhan menciptakan alam untuk kemudian diperlihara, diolah dan dimanfaatkan oleh manusia. Jadi sudah sewajarnya sebagai manusia kita harus peduli dengan terhadap alam. Karena alam memberikan manfaat yang sangat besar untuk hidup kita.

Berkaitan dengan nilai budaya persepsi manusai terhadap alam yaitu tunduk kepada alam, menjaga keselarasan dengan alamdan berusaha menguasai alam adalah sebagai berikut.

Bulan berkaca pada air. Kayu, lesu dan kaku.Tampak seperti aku

Bulan berkaca pada dedaunan. Bergoyang dan menari indah. Itu sepertikamu.

(F.S: CNT.A)

Larik di atas menggambarkan betapa indahnya pemandangan alam yang yang ada di lingkungannya.

Bulan malam tanpa tiang, menawan. Kapankah kubisa menggapai?

(F.S: CNT.A)

Larik di atas menggambarkan kecintaan kepada alam.

Seekor burung Merpati Hinggap di dahan harapan. Awan seakan menawan dilukisnya. Ia sedang memandangi Nuri-nuri. Yang bernyanyi. Tampak ia menaruh simpati. Ia jatuh hati.

(F.S: SMPT, CT)

Larik di atas menggambarkan simpati dan cita-cita seorang laki-laki kepada perempuan yang sedang jatuh hati. 
Dan sekarang aku kembali ke padang rumput. Bermain rakit dengan ikan, atau mencium angin. Sambil beristirahat dari kesibukan modern, menjauhi kebisingan motor yang merubah suara serulingku menjadi geraman jaman. Sungguh hanya ini yang bisa menjadi tempat aku berhenti. Dan disini pula rasanya tempat aku ingin mati, pergi. Meninggalkan mereka yang akan terus merajut dosa sampai tua Bangka.

(F.S:DMI)

Puisi di atas menggambarkan kerinduan kepada alam yang damai dan tentram.

Terkenang bebukitan hijauku tempat mengembalakan ternak

Tawa kanak-kanak dan pepohonan cengkih yang mengguratkan sejarah

(S.A: CNT.A)

bumi

betapa ia menyimpan pernik bayangan menggaris dalam tujuh langit rindu guncang ombak

wujud lidah-lidah laut

Talaga bumi, air kehidupan

(S.S: CNT.A)

Menampung titik embun dan hujan

Dzikir semesta pada hening bukit

Kicau burung memanggil sujud

Talagawarna

(Y.S: CNT.A)

tanah ramah, ramah berkah

bagi pengagumgandung

dan pemuji biji-biji padi

Musim ranum, senyum harum

bagi para pemuja pala, juga

rupa-rupa bunga.

(E.M: CNT.A)

Tetapi aku akan terus menabur

di setiap tanah kering

menumbukan bunga-bunga

menjelma ulang kehidupan

(L.K: TKN, MNFT.A)

Kenanglah aliran sungai yang memberimu
Gelak canda kanak-kanak

(S.A: CNT.A,)

Larik-larik di atas menggambarkan tentang kecintaan dan kegaguman manusia terhadap keindahan alam sehinggan ingin memanfaatkannya.

Gunung Kolecer*, tempatku menantang angin dari segala penjuru bumi

Tempat ku tabuhkan gendering jagad raya dengan ritme rerumputan

(S.A: MNFT.A)

Gunung kolecer adalah salah satu gunung di Cianjur utara, tepatnya berada di daerah Cikalongkulon. Biasanya di gunung tersebut menjadi tempat bermain kolecer warga sekitar karena selain daerahnya yang tinggi permukaannya juga anginnya besar, sehingga cocok dijadikan tempat untuk memainkan kolecer tersebut.

Nilai-nilai budaya yang berkenaan dengan pandangan manusia terhadap alam yaitu mencintai alam (CNTA.A), simpati/ merasakan apa yang orang lain rasakan (SMPT), cita-cita (CT), damai (DMI), tekun (TKN), dan memanfaatkan alam (MNFT.A).

\section{Hakikat hubungan Manusia dengan Sesamanya}

Manusia terlahir sebagai makhluk sosial. Dalam menjalani kehidupannya manusia tidak dapat hanya mengandalkan kekuatannya sendiri, tetapi harus membutuhkan manusia yang lainnya. Nilai budaya yang terkandung yang berkenaan dengan hakikat hubungan manusia dengan sesamanya yaitu ketergantungan pada sesamanya, ketergantugan kepada tokoh-tokoh atasan dan berpangkat, serta individualisme menilai tinggi usaha atas kekuatan sendiri. Berikut adalah puisinya.

Dan di hamparan tanah-tanah dunia. Keteguhanmu menjadi bunga yang tumbuh di setiap waktu

(D.M: BRN) 
Larik di atas menggambarkan sosok yang teguh dan berani diantara kerasnya kehidupan dunia.

Serupa cuaca,

Aku mencintaimu

Selalu terikat waktu

(F.D: KSH)

Mungkin aku terlalu merindukanmu

Mungkin aku terlalu dalam memimpikanmu.

(F.D: KSH)

Dari jauh, kulihat ibuku menangis, sendiri,

"Jangan menangis ibu!

Lihat betapa banyak bintang di sorga"

(F.D: KSH)

Aku selalu mengingatmu

Mengingat pelarian kita dalam hujan

Rintik-rintik itu ternyata menjadi titik

Untukmu, untuk kita

(F.D: KSH)

Maka dengan sepenuh doa

fajar ini ku lepaskan engkau menuju pengembaraanmu

Temui dirimu pada sungai wajahmu dangkal

Batu-batu disepuh ricik air

Cintamu berkabut rimba

Seperti terbasahi daun

Akar meremas tanah

Air mericik pelan-deras

Makhluk air berkaburan

Rumputan ciumi buih di samping

Katakan!

Bahwa kau adalah sungai itu

(I.S: KSH)

Larik-larik di atas menggambarkan kasih sayangnya manusia kepada sesamanya, ada yang mencintai pasangan lawan jenisnya, ada pulan kasih sayang yang diberikan kepada sosok seorang ibu yang telah banyak jasnya kepada seorang anaknya.

Maka dengan sepenuh doa

fajar ini ku lepaskan engkau menuju pengembaraanmu

melepaskan pelukanku yang selama ini menemani tidurmu mengeringkan air susu penyambung kehidupanmu

agar kau bisa berdiri sendiri

dan mampu menggantinya dengan kejernihan hujan

(S.A: DOA)

Larik-larik di atas menggambarkan sebuah ketulusan doa dari orang tua kepada anaknya demi bekal di masa mendatang.

Tiba-tiba aku ingin melihat ibu.

Menakjubkan, ibuku seorang bidadari.

Matanya bening

teduh.

Aku bisa melihat ada sinar di matanya,

Seperti matahari.

(F.D: KSH)

karena sayang semata

yang ditaburi cinta kepada darahdarah kecilku

kuwakili

indah pandangan dunia

(S.S: KSH)

Larik-larik di atas menggambarkan rasa kasih sayang orang tua kepada anaknya, begitupun sebaliknya.

Aku rasa

aku butuh seseorang

yang mencintaku

untuk menemukan tujuan

(E.M: CT)

Larik-larik di atas menggambarkan citacita atau pengharapan kepada seseorang yang dicintainya.

Aku pikir

aku butuh seseorang

yang begitu aku cintai

untuk menciptakan tujuan.

(E.M: MNCPT, CT)

Pak sini! Bagaimana kalau kita keluar dari dongeng ini. Saya bosan

memerankan ajing. Saya ingin menjadi tukang cerita saja. Tidak

menjadi bagian dari dongeng. Satu lagi pak! Orang yang pertama-tama

mendengarkannya tentulah harus bapak. Sebuah dongeng Negara lanjut 
usia. Disana Pak, Tikus tidak lagi

(Y.G: KSH)

diburu kucing.

(F.S: CT, USH)

Kenanglah bukit pendakian

Tempat nenek moyangmu bersemayam

(S.A: KSH)

Maka dengan sepenuh doa

fajar ini kulepaskan engkau menuju pengembaraanmu

melepaskan pelukanku yang selama ini menemani tidurmu

mengeringkan air susu penyambung

kehidupanmu

agar kau bisa sendiri

dan mampu menggantikannya dengan

kejernihan hujan

(S.A:DOA, BKL, BRN)

kidung gendang dan pencakkan gong

menyatu dengan raga

lenguh terompet bercerita keperkasaan

sang pribumi

dari orang-orang terdahulu

Di matamu,

Ngibing adalah kepasrahan pada tuhan

Penghormatan untuk nenek moyang

Karuhun, juga roh-roh alam

Dimana tembang itu telah melantun

Maka gerakan tubuh dirasuki rasa rindu

(S.A: MNGHRG, KSH , TSY)

Pada pucuk-pucuk Seni

Yang diwariskan guru-guru kabuyutan

Silat menjadi abdi

Pada jalan kekuasaan ilahi

(S.A: MNGHRG, TSY)

Ratu, telah kukirim padamu seekor burung. Pada hati dan tubunhnya bacalah

Selaksa musim, pohon-pohon yang tunduk pada ritus hujan dan angin.

Maka kuseru engkau untuk mendzikirkan kalimat-kalimat yang menyuarakan

keabadian

(Y.G: KSH)

Lalu kembara menari dengan gerak mencari api, mencari jejak para moyang.
Di musim gugur ini, dedaunan siap menggugurkan jasadnya.

Dan tentunya aku harus kembali menumbuhkan tunas harapan.

(A.Z: USH, CT)

Bersama rahim seorang perempuan

kuteruskan segala impianmu.

(D.M: BRN, CT)

Aku pejamkan mata

bathin yang tetap terjaga, rindu dan hasrat kutetapkan pada yang

menggenggam cinta,

telah sengaja kerinduan kulepas di

semilir waktu

(D.M: KHSY)

Larik di atas menggambarkan kesungguhan hati kepada sang pencipta. Karena sebagai makhluk harus taat kepada-Nya.

Sekuat tenaga kusapa dunia.

Seperti laparku

(F.D: BRN)

Kunikahkan segala kesunyian

Jiwa yang dililit liana

Dan sumpah terakhir atas sesal

Aku rancang di catatan sungai

kenangan itu

Lalu aku bercermin

(I.S: USH )

"Lihat betapa menakjubkan wajahku

Kecantikan tiada tara

Berbulu purba

Bertaring masa lalu

Darah....!"

(L.K: BKL)

Tetapi aku akan terus menabur

di setiap tanah kering

menumbuhkan bunga-bunga

menjelma ulang kehidupan

(L.K: USH)

Larik di atas menggambarkan usaha

manusia dalam memanfaatkan alamnya.

ia lanjutkan pertarungan

ia gibaskan tendangan kakinya yang kekar 


\section{tubuhnya melayang diatas angin}

Lalu melesat ke arah Mang Eucep

(S.A3: BRN)

Larik-larik di atas menggambarkan keberanian dalam pertarungan pencak silat demi memenangkan pertandingan tersebut.

Nilai-nilai yang berkenaan dengan hubungan manusia dengan sesamanya yaitu berani (BRN), kasih sayang (KSH), berdoa (DOA), bekal (BKL), cita-cita (CT), mencipta (MNCPT), usaha (USH), menghargai (MNGHRG), tasyakur (TSY), khusyu (KHSY), dan memanfaatkan alam (MNFTA).

\section{SIMPULAN}

Dari hasil proses pengumpulan data mengenai nilai-nilai budaya yang terdapat dalam puisi penyair Cianjur diperoleh kesimpulan sebagai berikut.
Pada puisi para penyair Cianjur terdapat nilai-nilai budaya yaitu bendung kejahatan (BND KJHT), tawadhu (TWDH), khusyu (KHSY), berdoa (DOA), tawakal (TWK), tasyakur (TSY), arraja'a (ARJ), bijaksana (BJK), dan mencegah penganiayaan (MNCG), usaha (USH), bekal (BKL), mencipta (MNCPT), menambah pengetahuan /wawasan (PNGT), berani (BRN) dan citacita (CT). damai (DMI), cinta alam (CNT.A), kasih sayang $(\mathrm{KSH})$, simpati/merasakan apa yang orang lain rasakan (SMPT), tekun (TKN), menghargai (MNGHRG), dan memanfaat alam (MNFT.A). Nilai-nilai budaya tersebut merupakan pilar budaya Cianjur, kemudian petuah dari para leluhur yang dapat diketahui dan dijadikan pedoman di dalam kehidupan.

\section{DAFTAR PUSTAKA}

Indriani, Ayu Astuti. 2013. Nilai-nilai Budaya dalam Novel Kubah Karya Ahmad Tohari. [online]. Tersedia: https://media.neliti.com/media/publications/192254-ID-nilai-nilaibudaya-dalam-novel-kubah-kar.pdf [09 Maret 2018]

Laelawati, Eulis Noer. 2015. "Cerita Rakyat Kampung Carengcem Serta Implementasi dalam Pembelajaran Drama di Kelas VIII SMP Pasundan Cianjur Tahun 2013-2014"Jurnal Alinea.IV, (7), 92-103.

Madania, dkk. 2006. Selalu Ada Rindu: Sastra Rindu Penyair Cianjur. Cianjur: Dewan Kesenian Jakarta.

Maulana, Edwar. 2014. Jejak. Bandung: Penerbit Literat.

Munsi, Mia Fatimatul. 2014. “Analisis Romantisme dan Nilai-nilai Budaya Antologi Puisi Kidung Leluhur Cianjur Karya Yusuf Gigan”. Tesis Pascasarjana Pendidikan pada FKIP Universitas Suryakancana:Tidak diterbitkan.

Nasution, M. S. A. dkk. 2015. Ilmu Sosial Budaya Dasar. Jakarta: Raja Grafindo.

Soelaeman, M. Munandar. 2010. Ilmu Budaya Dasar: Suatu Pengantar. Bandung: Refika Aditama.

Waluyo, Herman. J. 1995. Teori dan Apresiasi Puisi. Surakarta: Gelora aksara Pratama. 